Merck Sharp \& Dohme, Novartis, Pfizer, Tatiana Korotaeva Grant/research support from: Pfizer, Consultant of: Abbvie, BIOCAD, Bristol-Myers Squibb, Celgene, Eli Lilly, Janssen, Merck Sharp \& Dohme, Novartis, Novartis-Sandoz, Pfizer, UCB, Speakers bureau: Abbvie, BIOCAD, Bristol-Myers Squibb, Celgene, Eli Lilly, Janssen, Merck Sharp \& Dohme, Novartis, Novartis-Sandoz, Pfizer, UCB, Wim Noel Employee of: Janssen Pharmaceuticals NV, Petros Sfikakis Grant/research support from: Grant/research support from Abvie, Novartis, MSD, Actelion, Amgen, Pfizer, Janssen Pharmaceutical, UCB, Elke Theander Employee of: Janssen-Cilag Sweden AB, Josef S. Smolen Grant/research support from: AbbVie, AstraZeneca, Celgene, Celltrion, Chugai, Eli Lilly, Gilead, ILTOO, Janssen, Novartis-Sandoz, Pfizer Inc, Samsung, Sanofi, Consultant of: AbbVie, AstraZeneca, Celgene, Celltrion, Chugai, Eli Lilly, Gilead, ILTOO, Janssen, Novartis-Sandoz, Pfizer Inc, Samsung, Sanofi, Laure Gossec Grant/research support from: Lilly, Mylan, Pfizer, Sandoz, Consultant of: AbbVie, Amgen, Biogen, Celgene, Janssen, Lilly, Novartis, Pfizer, Sandoz, Sanofi-Aventis, UCB DOI: 10.1136/annrheumdis-2020-eular.2771

\section{SAT0433 TRIAL SIMULATION TO INFORM ENROLLMENT CRITERIA AND OUTCOME MEASURES FOR PRAGMATIC TRIALS IN PSA}

A. Ogdie $^{1}$, S. Weinstein ${ }^{1}$, L. C. Coates ${ }^{2}$, P. Helliwell ${ }^{3}$, A. Stephens-Shields ${ }^{1}$. ${ }^{1}$ University of Pennsylvania, Philadelphia, United States of America; ${ }^{2}$ University of Oxford, Oxford, United Kingdom; ${ }^{3}$ University of Leeds, Leeds, United Kingdom

Background: Randomized controlled trials (RCTs) in psoriatic arthritis (PsA) have traditionally enrolled a homogenous subgroup of patients with more polyarticular disease, and the outcome measure used in PsA RCTs (ACR20) may not be ideal to measure differences between two active therapies nor capture change in patients with lower joint counts.

Objectives: We conducted a simulation study to determine how changing the inclusion criteria and the primary outcome measure would impact the outcome of a future RCT.

Methods: We used the Tight Control of PsA (TICOPA) ${ }^{1}$ trial to inform simulation of two hypothetical head-to head trials comparing MTX to TNFi with 100 patients per arm. Within TICOPA, we identified MTX and TNFi new users; the visit at drug initiation became the hypothetical trial baseline visit, and the follow up visit was 12 weeks later. These data informed prediction models to simulate enrolled patients. We utilized propensity score-adjusted outcome models to account for potential confounding by indication. Trial 1 , modeled after the SEAM-PSA trial, ${ }^{2}$ used typical enrollment criteria ( $\geq 3$ tender joint count (TJC) and $\geq 3$ swollen joint count (SJC)) ${ }^{2}$; Trial 2 required $\geq 1 \mathrm{TJC} / \mathrm{SJC}$. ${ }^{1}$ For each trial, five binary outcomes were simulated: ACR20, Disease Activity in PsA (DAPSA), clinical DAPSA (cDAPSA), Routine Assessment of Patient Index Data (RAPID3), and PsA Disease Activity Score (PASDAS), where low disease activity was the cutoff for continuous measures. Each hypothetical trial was simulated 1000 times, and the distribution of estimated effects was summarized using standard summary statistics and graphs.

Results: Among 188 patients in TICOPA, 179 patients initiated MTX, and 43 patients initiated TNFi within the first 36 weeks. Among these, 107 MTX initiators and $15 \mathrm{TNFi}$ initiators had $\geq 3 \mathrm{TJC}$ and $\geq 3 \mathrm{SJC}$ at drug initiation. Baseline characteristics of those in the "severe" ( $\geq 3$ TJC and $\geq 3$ SJC) and not severe (not meeting $\geq 3$ TJC and $\geq 3$ SJC) are shown in Table 1. Among "severe" patients, the mean probability of achieving ACR20 across simulations was approximately 0.27 in both arms and the observed relative risk (RR) TNFi vs MTX severe cohort across simulations was 1.0, IQR 0.84-1.17 (the RR in the SEAM trial at 24 wks was $1.20,95 \% \mathrm{Cl}: 1.05-1.35)$. In the "full cohort", the median RR was 1.0, IQR 0.811.04. Trials using PASDAS, CDAPSA, and RAPID3 were more likely to differentiate between TNFi and MTX in the severe cohort (figure) but in the full cohort the results favored $\mathrm{MTX}$

Table 1. Observed characteristics at drug initiation

\begin{tabular}{|c|c|c|c|c|c|c|}
\hline & \multicolumn{3}{|c|}{ Severe $(n=148)$} & \multicolumn{3}{|c|}{ Not Severe $(n=75)$} \\
\hline & $\operatorname{MTX}(n=127)$ & TNFi $(n=21)$ & SMD & MTX $(n=52)$ & TNFi $(n=23)$ & SMD \\
\hline \multicolumn{7}{|l|}{ TICOPA Arm (no. (\%)) } \\
\hline Standard Care & $57(45 \%)$ & $4(19 \%)$ & 0.58 & $28(54 \%)$ & $3(13 \%)$ & 0.96 \\
\hline Intensive Management & $70(55 \%)$ & $17(81 \%)$ & & $24(46 \%)$ & $20(87 \%)$ & \\
\hline Female (no. (\%)) & $65(51 \%)$ & $11(52 \%)$ & 0.02 & $22(42 \%)$ & $12(52 \%)$ & 0.20 \\
\hline TJC (mean (SD)) & $17.8(15.3)$ & $19.1(17.3)$ & 0.08 & $3.5(4.6)$ & $16.4(19.1)$ & 0.93 \\
\hline SJC (mean (SD)) & $9.2(7.4)$ & $10.2(12.1)$ & 0.10 & $2.4(3.4)$ & $2.2(2.4)$ & 0.05 \\
\hline
\end{tabular}

Severe $=\geq 3$ tender and $\geq 3$ swollen joints

Not-severe $=<3$ tender or $<3$ swollen joints

*Pseudo-baseline characteristics were at the time of drug initiation. In cases where the patient started a TNFi between visits, these were the values at the previous visit.

Abbreviations: $\mathrm{SMD}=$ standardized mean difference, $\mathrm{TJC}=$ tender joint count, $\mathrm{SJC}=$ swollen joint count
Conclusion: Including patients with lower joint counts in an RCT reduced the ability to detect change with therapy. Additionally, among the outcome measures used to detect a difference between two active therapies, PASDAS, cDAPSA and RAPID3 outperformed ACR20.

References:

[1] Coates et al. Lancet 2015; 2. Mease et al. Arthritis Rheumatol 2019

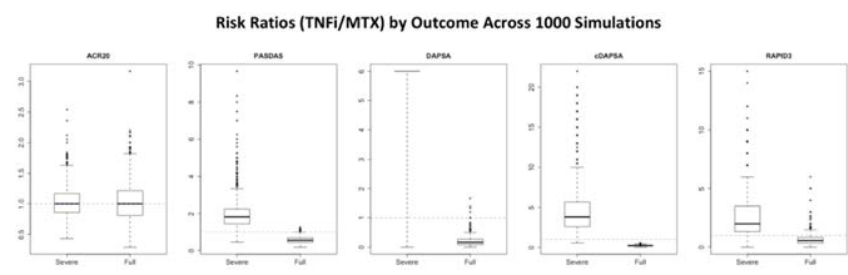

Figure 1. Risk Ratios (TNFi vs MTX) by Outcome Across 1000 Simulations

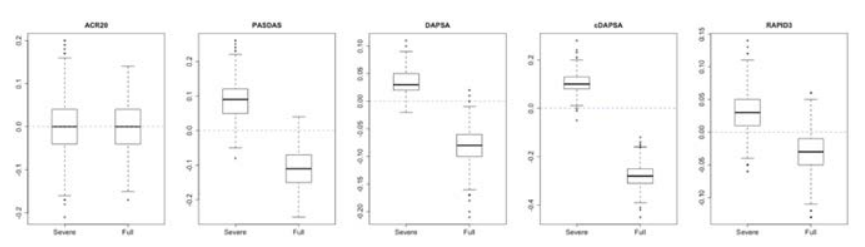

Figure 2. Risk Differences (TNFi - MTX) by Outcome Across 1000 Simulations

Disclosure of Interests: Alexis Ogdie Grant/research support from: Pfizer Novartis, Consultant of: Abbvie, Amgen, BMS, Celgene, Corrona, Janssen, Lilly, Pfizer, Novartis, Sarah Weinstein: None declared, Laura C Coates: None declared, Philip Helliwell: None declared, Alisa Stephens-Shields: None declared DOI: 10.1136/annrheumdis-2020-eular.3353

\section{SAT0434 MINIMAL CLINICALLY IMPORTANT DIFFERENCE IN OUTCOME MEASURES FOR USE IN CLINICAL CARE AND PRAGMATIC TRIALS IN PSA}

A. Ogdie ${ }^{1}$, M. E. Husni ${ }^{2}$, J. Scher ${ }^{3}$, E. Craig ${ }^{1}$, S. Reddy ${ }^{3}$, J. A. Walsh ${ }^{4}$. ${ }^{1}$ University of Pennsylvania, Philadelphia, United States of America; ${ }^{2}$ Cleveland Clinic, Cleveland, United States of America; ${ }^{3}$ New York University, New York, United States of America; ${ }^{4}$ University of Utah, Salt Lake City, United States of America

Background: While several outcome measures have been studied for use in clinical studies of psoriatic arthritis, little is known about thresholds of meaning such as minimal clinically important improvement (MCII).

Objectives: To investigate the distribution of scores for candidate outcome measures for pragmatic trials in PsA and to calculate the MCII for each outcome measure.

Methods: We performed a longitudinal cohort study within the Psoriatic Arthritis Research Consortium (PARC), a multi-center study based in the US. Patients completed validated PROs (patient reported outcomes) and rheumatologists completed skin, joint, enthesis and dactylitis scores at therapy initiation and follow up 12-16 weeks later. In addition, patients completed a global assessment of response at the follow up visit, categorizing their status as improved, stayed the same, or worsened and then ratied the importance of the change on a scale from $0-7 .^{1}$ We then calculated and plotted the change in each of the following measures: Routine Assessment of Patient Index Data (RAPID3), clinical Disease Activity of Psoriatic Arthritis (cDAPSA), Patient Reported Outcome Measure Information System (PROMIS) Global Health short form (10a) physical health $(\mathrm{PH})$ subscore, patient pain assessment, patient global assessment (0-10 NRS) and physician global assessments (0-10 NRS) of the joints and overall. We calculated the MCII as the mean change in score (with $95 \%$ confidence interval) among patients who reported improvement and rated the level of improvement as "almost none/hardly at all" or "a little important." Additionally, we calculated Spearman's correlation coefficients between the measures and the global assessment of response.

Results: Among 148 unique patients, 233 therapy change visits were eligible for analysis. The average age was 52.5 years, $52 \%$ were female and mean BMI was 29.6. Baseline RAPID3 was 11.1 (SD 6), cDAPSA 17.9 (SD 13.9), PROMIS PH 42 (SD 8), patient global 4.2 (SD 2.5), TJC 5.9 (SD 7.5), and SJC 2.9 (SD 4.5). TNFi comprised $61 \%$ of drug initiations, $21 \%$ were IL $17 \mathrm{i}$ and the remainder were other biologics and oral systemic therapies. At follow up, $63(27 \%)$ patients rated themselves as improved whereas 103 (44\%) stayed the same and $67(29 \%)$ reported 